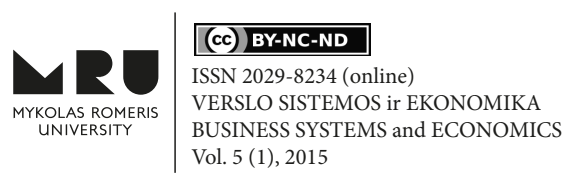

\title{
LEGAL AND SHADOW ECONOMIES INTERACTION MODEL: ANALYSIS OF PHASE TRAJECTORY PROJECTION
}

\author{
Vasyl GRYGORKIV \\ Yuriy Fedkovych Chernivtsi National University, Department of Economic Modelling \\ Kotsjubynskyi 2, Chernivtsi 58012, Ukraine \\ E-mail: v.grygorkiv@chnu.edu.ua \\ Igor VINNYCHUK \\ Yuriy Fedkovych Chernivtsi National University, Department of Economic Modelling \\ Kotsjubynskyi 2, Chernivtsi 58012, Ukraine \\ E-mail: i.vinnychuk@chnu.edu.ua
}

doi:10.13165/VSE-15-5-1-06

\begin{abstract}
The article is devoted to the development of theoretical, methodological and methodical approaches to modeling of interaction processes of legal and shadow components of the economy. In this paper, the mathematical model of legal and shadow economies interaction, taking into account the economic structure of society, is built.
\end{abstract}

Keywords: shadow economy, the economic structure of society, phase trajectory, economic dynamics, simulation.

JEL Classification: O17, E26.

\section{Introduction}

On the current stage of development of Ukrainian economy, the extensive development of economic relations, covering unlicensed, unregulated and illegal business activities, can be observed. These relationships are called shadow economy and make a significant impact on all socio-economic processes taking place in society. The shadow sector significantly influences all aspects of economic activity, political and social life of each country. In such circumstances, the studies of the interaction between legal and informal sectors are topical. Without considering this interaction, economists cannot provide scientific economic analysis at the macro and micro levels and effective decision-making. In the last years, many studies have been conducted dedicated to the shadow economy investigation, in which different approaches and instruments are used.

One of the most common approaches is panel data usage to understanding what factors influence shadow economy rate. Alm and Embaye used a dynamic panel data model for estimating the shadow economy using the currency demand method (Alm and Embaye, 2013). They found out that the currency to M2 ratio tends to be higher. The higher is the 
economic return from underreporting, the weaker the enforcement capacity of the tax administration and the higher the inflation rate. The results also show that the estimated size of the shadow economy varies significantly by income level, with lower-income countries having a larger shadow economy.

Gonzalez-Fernandez and Gonzalez-Velasco, using panel data, analyzed the relationship between the shadow economy and corruption as determinants of public debt (Gonzalez-Fernandez and Gonzalez-Velasco, 2014). Their results show that the volume of the shadow economy and corruption both have positive and significant impacts on regional public debt, but corruption impact is lower that of the shadow economy.

In the article "A cross-section approach to measuring the shadow economy", authors used the cross-section survey data based on individual responses to estimate the relative size of shadow economy household income as a proportion of declared income in Slovakia and Czech Republic (Orviska, et al., 2006).

In transitional societies, a high level of the shadow economy can be observed. In this connection, particular importance should be put on modelling the shadow and legal economies interaction.

Vitlinskii and Koliada have constructed the mathematical model of dynamics of cooperation of corruption, shadow and legal economies (Vitlinskii and Koliada, 2010). They have got analytical expressions of majorant type in relation to the evaluation of component's volumes and a degree of risk of their co-existence.

Koljada and Semashko have extended the above stated results using a planar dynamic model, which describes the economic state of society where official and illegal economies co-exist (Koliada and Semashko, 2014). They obtained formulas for the risk assessment coexistence of legal and shadow economies. The result can be used to predict at arbitrary time t. The quality of prediction depends on the coefficients of the mathematical model, initial conditions and scope of the legal economy.

Gubarieva presented another methodical approach to the construction of scenarios of economic development of the regions of Ukraine that is based on the concept of system dynamics, takes into account the impact of the shadow economy and enables to select a set of government regulation instruments (Gubarieva, 2013). The proposed simulation model reflects the fundamental processes taking place in the region in forms of material, financial and information flows. Leaning on the results of the model operation, the author substantiated the choice of scenarios of socio-economic development of Kharkov region, taking into account the shadow economy.

Svetunkov in his book "Complex-valued Modeling in Economics and Finance" described the possibility of modeling the shadow economy by means of complex-valued functions (Svetunkov, 2012). Using the theory of complex numbers, the model to estimate the cost of fixed assets used in illegal production, the number of employees involved in the shadow economy and GDP of the shadow economy were constructed. However, calculations in this model are fairly arbitrary due to the lack of reliable data.

These publications, as well as several others, are aimed either at assessing the impact of the shadow economy to economic development, or estimating quantities or determining how different social and economic changes influence the shadow economy. The aim of this research is to study the direct interaction processes between legal and shadow economies, taking into account the economic structure of society. For this goal, the mathematical model of the economy with the shadow sector was constructed. 


\section{Model of legal and shadow economies interaction with extended economic structure of society}

The authors of the present study have designed the general model for the legal and shadow economies interaction that develops and expands the results of the macro-economic dynamics modeling (Cherniavskii, et al., 2002), including the results obtained in previous works (Grygorkiv and Vinnychuk, 2008; Grygorkiv, 2008; Buyak and Vinnychuk, 2009; Vinnychuk and Ziukov, 2013).

Let us assume that society can be structured by groups of its members (elements) that had or have a relation to the economy and are divided into the following groups (clusters): non-working pensioners (their number is $\left(n_{0}\right)$ ); real sector workers $\left(n_{1}\right)$; business owners or entrepreneurs $\left(n_{2}\right)$; workers of budget organizations (employees) $\left(n_{3}\right)$; pensioners working in the real sector $\left(n_{4}\right)$; pensioners working in budget organizations $\left(n_{5}\right)$; elite (high-ranking officials and executives) $\left(n_{6}\right)$.

Let $\alpha_{i} \quad\left(0<\alpha_{i} \leq 1\right)$ be a part of saving the $i$-th group representatives $(i=\overline{0,5})$ that they use to buy legal products, and $\left(1-\alpha_{i}\right)$ be a part of savings used to buy illegal products. Demand function is denoted by $G_{i}\left(\alpha_{i} \frac{x_{i}}{p}\right)$ for legal goods and services, and by $G_{i}^{*}\left(\left(1-\alpha_{i}\right) \frac{x_{i}}{p}\right)$ demand function is denoted for shadow product or service, and $G_{i}(0)=G_{i}^{*}(0)=0$. Note that the price of the aggregate good or service is considered to be the same everywhere. Businessmen allocate their savings $x_{2}$ to three parts, which are constants for the simulated period of time: $\alpha_{2}$ is a part used for personal needs, $\varepsilon_{2}$ is a part used for bribes, $\sigma_{2}$ is a part used for production needs $\left(\alpha_{2}+\varepsilon_{2}+\sigma_{2}=1\right)$. Part of the money $\beta \sigma_{2} x_{2}$ goes to shadow production, and the rest $(1-\beta) \sigma_{2} x_{2}$ goes to legal production $(0 \leq \beta \leq 1)$.

The value of legal $F_{L}\left(\mu_{L}\right)$ and shadow $F_{S}\left(\mu_{S}\right)$ products is described by production functions that are dependent on capital intensity of one workplace.

Let us describe differential equations that model the changes in savings and goods prices. The rate of change of pensioners' savings is equal to the difference between their income and consumption expenditures and possible bribes:

$$
\frac{d x_{0}}{d t}=p\left(r_{0}-G_{0}\left(\frac{\alpha_{0} x_{0}}{p}\right)-G_{0}^{*}\left(\frac{\left(1-\alpha_{0}\right) x_{0}}{p}\right)\right) .
$$

Workers of the real sector have a legal income (salary $r_{1}$ ) and a possible shadow income (salary $r_{1}^{*}$ ). Their costs consist of the income tax $k r_{1}$ ( $k$ is the income tax rate in the legal economy), "shadow taxes" $k^{*} r_{1}^{*}$ ( $k^{*}$ is the income tax rate in the shadow economy; it could be a part of the income used for shadow structures), and costs for consumption and possible bribes. A variation of $x_{2}$ can be modeled by the differential equation:

$$
\frac{d x_{1}}{d t}=p\left[r_{1}(1-k)-G_{1}\left(\frac{\alpha_{1} x_{1}}{p}\right)+r_{1}^{*}\left(1-k^{*}\right)-G_{1}^{*}\left(\frac{\left(1-\alpha_{1}\right) x_{1}}{p}\right)\right] .
$$


Incomes of entrepreneurs depend on the product sales and corresponding costs. This volume consists of products sold in the market to consumers of all social groups and products ordered by the government $\varphi$.

The first part of the legal sector expenditure includes expenses for salaries of workers of the second and fifth social groups (it is proportional to the production output in the legal economy with the coefficient $\psi$ ) and payroll tax ( $k_{1}$ is the tax rate), and the other part of costs is production costs ( $\lambda$ is the share of these costs) and the value-added tax ( $k_{2}$ is the tax rate). A similar situation is in the shadow economy, where the first part of the costs is the salary of the second and fifth groups (it is proportional to the production output in the shadow economy with the coefficient $\psi^{*}$ ) and "the shadow payroll tax" on "the shadow salary fund" ( $k_{1}^{*}$ is the tax rate). The third part includes costs for bribes. The dynamics of $x_{2}$ can be described by the next equation:

$$
\begin{aligned}
& \frac{d x_{2}}{d t}=\frac{p}{n_{2}}\left\{\sum_{\substack{i=0 \\
i \neq 2}}^{6} n_{i} G_{i}\left(\frac{\alpha_{i} x_{i}}{p}\right)+\varphi-G_{2}^{*}\left(\varepsilon_{2} \frac{x_{2}}{p}\right)-\psi\left(n_{1}+n_{4}\right) F\left(\frac{n_{2}}{n_{1}+n_{4}} \sigma_{2}(1-\beta) \frac{x_{2}}{p}\right)\left(1+k_{1}\right)-\right. \\
& -\psi^{*}\left(n_{1}+n_{4}\right) F^{*}\left(\frac{n_{2}}{n_{1}+n_{4}} \sigma_{2} \beta \frac{x_{2}}{p}\right)\left(1+k_{1}^{*}\right)-\left(n_{1}+n_{4}\right) F\left(\frac{n_{2}}{n_{1}+n_{4}} \sigma_{2}(1-\beta) \frac{x_{2}}{p}\right)\left(\lambda+k_{2}\right)- \\
& \left.-\left(n_{1}+n_{4}\right) F^{*}\left(\frac{n_{2}}{n_{1}+n_{4}} \sigma_{2} \beta \frac{x_{2}}{p}\right)\left(\lambda^{*}+k_{2}^{*}\right)\right\}
\end{aligned}
$$

The officials' income includes salary $r_{3}$ reduced by the tax rate $k$, and a smaller part $\delta_{3}$ of the total amount of bribes and the value $d_{3}^{*}$ of the misappropriated state property. Their costs are composed of goods consumption and possible bribes. Thus, the dynamic equation for the savings of a person from the fourth group is as follows:

$$
\begin{aligned}
& \frac{d x_{3}}{d t}=p\left\{r_{3}(1-k)+\delta_{3} \frac{\sum_{i=0, i \neq 2}^{6} n_{i} G_{i}^{*}\left(\left(1-\alpha_{i}\right) x_{i} / p\right)+n_{2} G_{2}^{*}\left(\varepsilon_{2} \frac{x_{2}}{p}\right)}{\left(n_{3}+n_{5}+n_{6}\right)}+d_{3}^{*}-\right. \\
& \left.-G_{3}\left(\frac{\alpha_{3} x_{3}}{p}\right)-G_{3}^{*}\left(\frac{\left(1-\alpha_{3}\right) x_{3}}{p}\right)\right\},
\end{aligned}
$$

where $d_{3}^{*}$ is the amount of misappropriated public funds by this group's members.

Pensioners working in the real sector receive a taxable pension, legal salary and extra "shadow" income. Their costs include consumption and possible bribes. Changes of such pensioner savings can be described by the equation:

$$
\frac{d x_{4}}{d t}=p\left[r_{0}+r_{1}(1-k)+r_{1}^{*}\left(1-k^{*}\right)-G_{4}\left(\frac{\alpha_{4} x_{4}}{p}\right)-G_{4}^{*}\left(\frac{\left(1-\alpha_{4}\right) x_{4}}{p}\right)\right] .
$$


Pensioners working in budget organizations receive nontaxable pensions $r_{0}$, taxable salaries, possible bribes (share $\delta_{5}$ ) and misappropriated public funds $d_{5}^{*}$. Expenses consist of consumption and costs for possible bribes. The dynamics of their savings is formalized as follows:

$$
\begin{aligned}
& \frac{d x_{5}}{d t}=p\left\{r_{0}+r_{3}(1-k)+\delta_{5}\left(\frac{\sum_{i=0, i \neq 2}^{6} n_{i} G_{i}^{*}\left(\left(1-\alpha_{i}\right) x_{i} / p\right)+n_{2} G_{2}^{*}\left(\varepsilon_{2} \frac{x_{2}}{p}\right)}{\left(n_{3}+n_{5}+n_{6}\right)}\right)+d_{5}^{*}-\right. \\
& \left.-G_{5}\left(\frac{\alpha_{5} x_{5}}{p}\right)-G_{5}^{*}\left(\frac{\left(1-\alpha_{5}\right) x_{5}}{p}\right)\right\}
\end{aligned}
$$
Elite savings $x_{6}$ can be found from the condition of the constancy $\sum_{i=0}^{6} n_{i} x_{i}=d$ of the
total amount of money $d$ in society.

The unit price of the aggregate product may be considered as constant in the studied period of time, but it also can be modeled using a differential equation, which reflects its dependence on the supply-demand balance of goods in the market:

$$
\begin{aligned}
& \frac{d p}{d t}=v_{p}\left\{\sum_{i=0}^{6} n_{i} G_{i}\left(\frac{\alpha_{i} x_{i}}{p}\right)+\varphi-\right. \\
& \left.-\left(n_{1}+n_{4}\right) F\left(\frac{n_{2}}{n_{1}+n_{4}} \sigma_{2}(1-\beta) \frac{x_{2}}{p}\right)-\left(n_{1}+n_{4}\right) F^{*}\left(\frac{n_{2}}{n_{1}+n_{4}} \sigma_{2} \beta \frac{x_{2}}{p}\right)\right\}
\end{aligned}
$$

де $v_{p}$ - proportionality factor describing the lag of the market.

To solve the system of differential equations [1] to [7], it is necessary to specify the initial conditions. Consider that $x_{0}(0), x_{1}(0), x_{2}(0), x_{3}(0), x_{4}(0), x_{5}(0), p(0)$ are known and have specific models of the functions $F, F^{*}, G_{i}, G_{i}^{*}(i=\overline{0,6})$ and values of the parameters $\propto, n_{i^{*}}(i=\overline{0,6}), r_{0} . r_{1}, r_{3}, \alpha_{i}(i=\overline{0,6}), r_{1}^{*}, k, k^{*}, \beta, v_{p}, d_{3}^{*}, d_{5}^{*}, \varphi$, $k_{1}, k_{2}, k_{1}^{*}, k_{2}^{*}, \psi, \psi^{*}, \lambda, \lambda^{*}, d$.

\section{Empirical analysis}

To analyze the interaction patterns of shadow and legal economies interaction, information system "Shadow economy" was developed. It includes a core based on MatLab functions and graphical user interface designed using Microsoft Visual Studio 2012. The information system "Shadow economy" is used to set the initial conditions of the models [1] to [7] and to construct trajectories of model solutions.

To expand and complement the results of simulation experiments, the authors of the present study have investigated the dynamics of demand for a legal product or service for each social group $G_{i}\left(\frac{\alpha_{i} x_{i}}{p}\right)(i=\overline{0,6})$. In addition, the dynamics of purchasing power for each social group $\frac{x_{i}}{p}(i=\overline{0,6})$ was analyzed. 
The experiments show that the purchasing power of all groups, except business owners, first increases and then starts to decrease to a certain horizontal asymptote.

In the context of the growth of the shadow economy, the decrease of purchasing power is faster than in the context of the shadow economy legalization. An example of this pattern is the dynamics of the purchasing power of non-working pensioners (Fig. 1).

Figure 1. The purchasing power of non-working pensioners

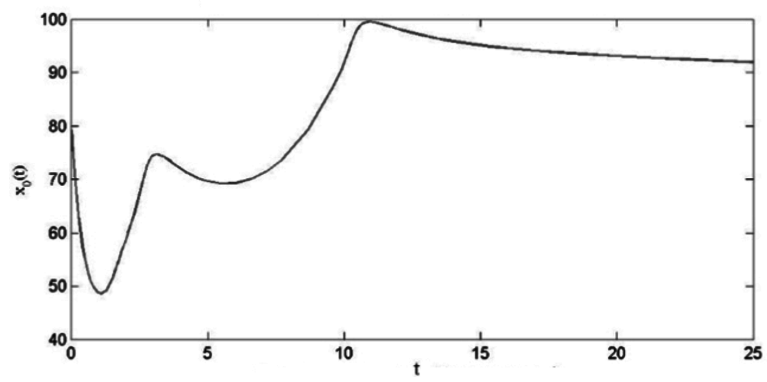

a)

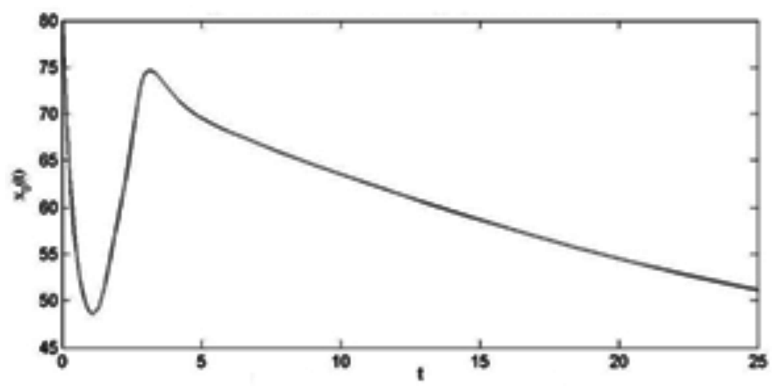

b)

Source: generated by the authors using the information system "Shadow economy" (2014)

The authors also have investigated the dynamics of demand for legal goods and services for different social groups. It appeared that with the growth of the shadow economy the demand for legal goods and services of all groups, except for business owners or entrepreneurs, first increases to a local maximum, which coincides with the point of the maximum of the aggregate product price, and then begins to decrease the horizontal asymptote. This level of demand for legal products is equal to the purchase of goods of the second category.

Based on the model solutions that are found in the time interval $t \in\left[t_{0}, t_{n}\right]$, where $t_{0}$ - initial time period, $t_{n}$ - final time period, the projections of phase trajectories are constructed on the plane $\left(x_{i}, x_{j}\right)(i, j=\overline{1,10}, i \uparrow j)$. These projections explain the properties of the found solutions of the interaction model of legal and shadow components.

Figure 2 shows a graph of phase trajectory projection to the plane $\left(x_{4}, x_{3}\right)$ (savings of business owners and workers of budget organizations). This graph illustrates the dynamics of the relationship between savings of two market participants belonging to different groups 
according to the nature of their economic activity. The circle in the graph defines the initial conditions of the experiment.

Figure 2. The phase trajectory projection of the SL-model on a plane $\left(x_{4}, x_{3}\right)$

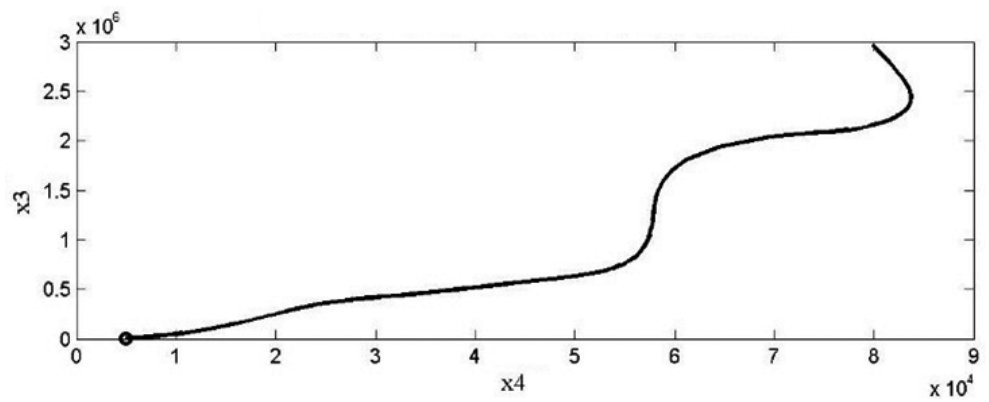

Source: generated by the authors using the information system "Shadow economy"

The graph shows the piecewise-linear increase of both indicators. It should be noted that the point moves along one coordinate and then along the other. This indicates an order in the change of savings, at one moment - the workers of budget organizations, at another business owners. These fluctuations of savings are in the opposite phase. This change is characteristic of groups in which financial viability is significantly different.

Let us also consider the projection of the solution to the plane $\left(x_{5}, x_{2}\right)$, reflecting the savings of pensioners working in the real sector and the real sector workers (Fig. 3 ).

Figure 3. The phase trajectory projection of the SL-model on a plane $\left(x_{5}, x_{2}\right)$

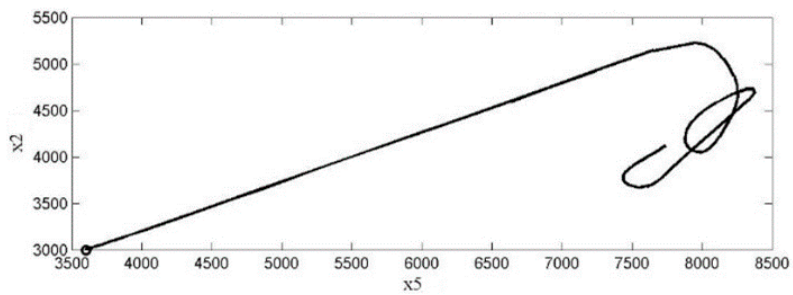

a)

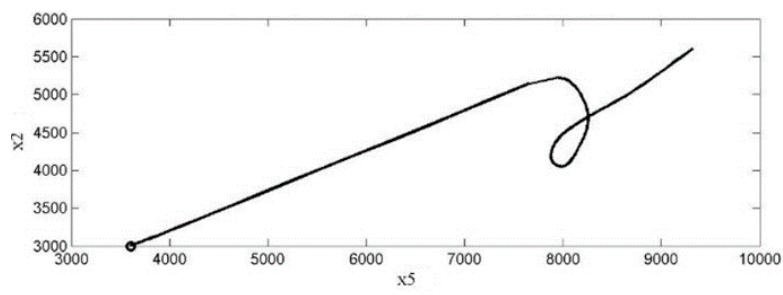

b)

Source: generated by the authors using the information system "Shadow economy" 
In this graph, in terms of reducing the shadow economy, two "turning points" can be seen, in which fluctuations of dynamic variables begin. In one of these points, $x_{2}(t)$ begins to decrease more rapidly, and $x_{5}(t)$ decreases in another. However, after a drop in savings, they again begin to grow. These oscillations occur in some range, which can be considered in some sense as a point of equilibrium.

Let us analyze the phase trajectory projections on the planes formed by dynamic variables modeling savings of groups receiving their income from the state and the shadow economy rate $\beta$. A typical illustration is shown in Figure 4.

Figure 4. The phase trajectory projection of the SL-model on a plane $\left(\beta, x_{1}\right)$ (shadow economy ratio $\beta$ and pensioners' savings)

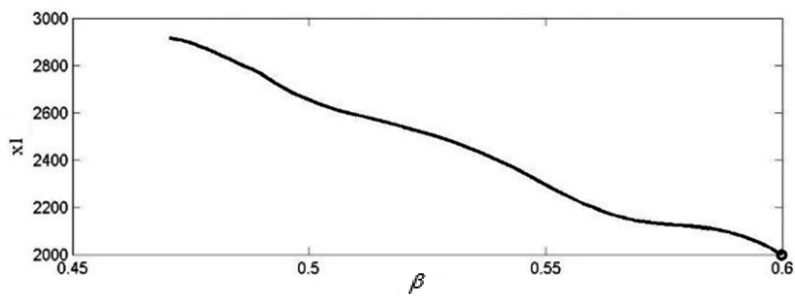

a)

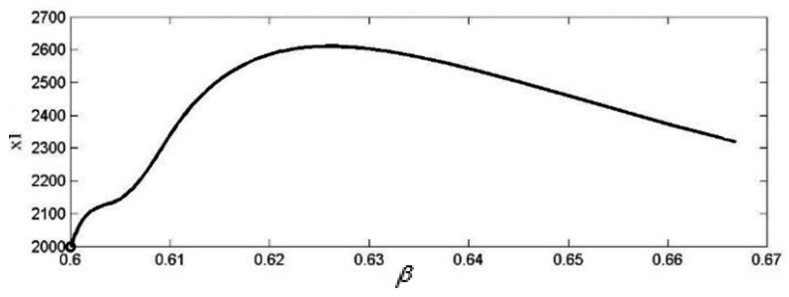

b)

Source: generated by the authors using the information system "Shadow economy"

Figure 4 illustrates the phase trajectory projection of the model to the plane $\left(\beta, x_{1}\right)$, which reflects the ratio $\beta$ and the pensioners' savings. Figure 4 shows the projection in the case of reducing the shadow economy. Obviously, in the process of the reduction of the shadow economy, the incomes increase, so there is an inverse relationship. In the case of growth of the shadow economy (Fig. 4b), the growing distance between points in the initial and final time can be observed. As the graph shows, increasing the shadow economy rate brings a short-term effect of increasing savings, but in the future growth of the shadow economy leads to a decline in savings.

Let us analyze phase trajectories on the plane of dynamical variables that model the price of the aggregated product and the savings of different groups. In the case of the price of the aggregate product and savings of employees of the real sector (Fig. 5), there is a simultaneous linear increase in both variables and their linear reduction. In terms of reducing the shadow economy, four turning points, where the dynamics of processes is changed, can be observed. Between the price of the aggregate product and the savings of employees of the 
real sector, there is a close correlation since a change in the direction of the price trajectory changes the direction of savings. The owners have an ability to increase salaries in the case of good financial results, which depends on the products' price. These fluctuations are cyclical in nature.

Figure 5. The phase trajectory projection of the SL-model on a plane $\left(p, x_{2}\right)$

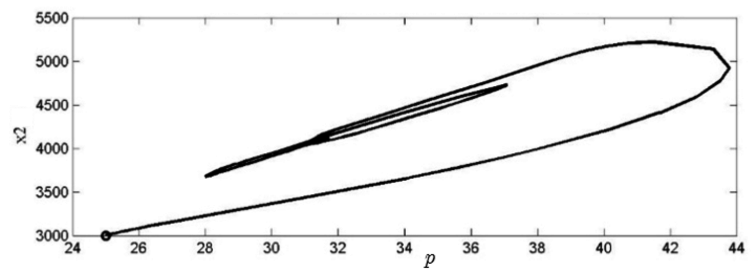

a)

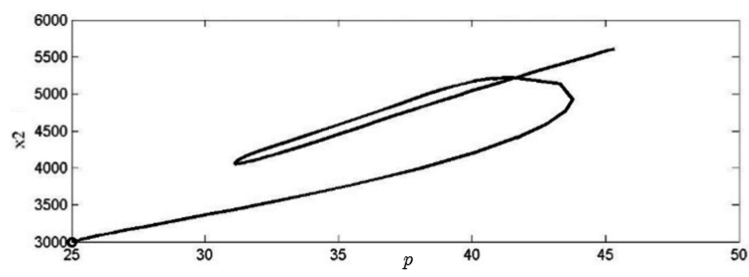

b)

Source: generated by the authors using the information system "Shadow economy"

The phase trajectory projections on the plane formed by dynamic variables that model the price of the aggregate product and savings of non-working pensioners, business owners, workers of budget organizations, pensioners working in budget organizations reflect similar trends in the case of shadow economy reducing (typical illustration in Fig. 6a). Against the background of price fluctuations, savings of these social groups reflect an upward trend. In terms of reducing the shadow economy, financial capacity of the state is growing and the state is able to provide people who depend on the public sector. The much faster growth of savings at a time when the price of the aggregate product tends to decrease also can be observed.

Figure 6. The phase trajectory projection of the SL-model on a plane $\left(p, x_{4}\right)$

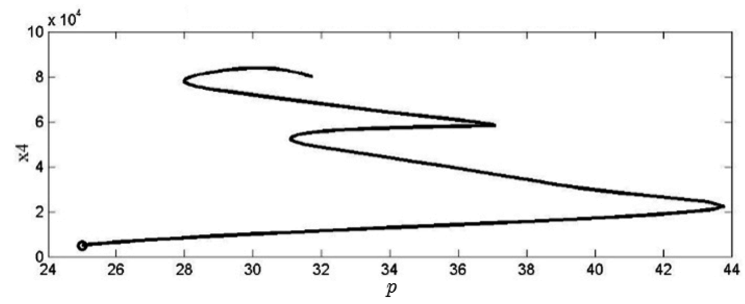

a) 


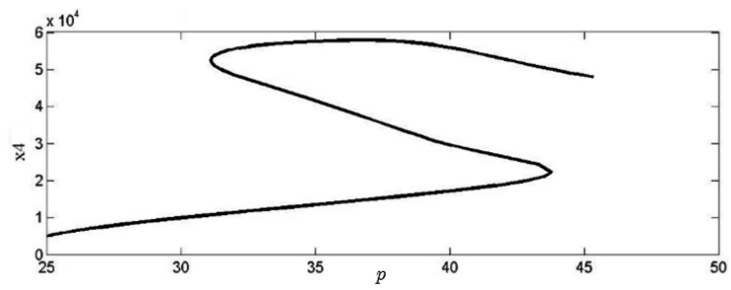

b)

Source: generated by the authors using the information system "Shadow economy"

In terms of the growth of the shadow economy for savings of non-working pensioners, workers of budget organizations, pensioners working in budget organizations, there is a similar trend and trajectory has two turning points (Fig. 6b). At first, in terms of price growth, savings of these groups increase slightly, but in the case of price reduction savings begin to grow faster. Further increase in price leads to a decline in savings, which is undesirable trend in economics.

Figure $7 \mathrm{~b}$ shows the phase trajectory projection of model solutions on the plane of dynamical variables that model businessmen savings and price of the aggregate product. As the figure shows, after a rather slow growth of savings in terms of a significant price increase, savings and price are in the opposite phase. After a turning point, the price and the businessman savings begin to grow in contrast to the situation, when there is reducing of the shadow economy and the savings of the above mentioned four groups tend to increase, in the case of the shadow economy growth only businessman savings tend to increase, confirming their benefits from the shadow economy.

Figure 7. The phase trajectory projection of the SL-model on a plane $\left(p, x_{3}\right)$

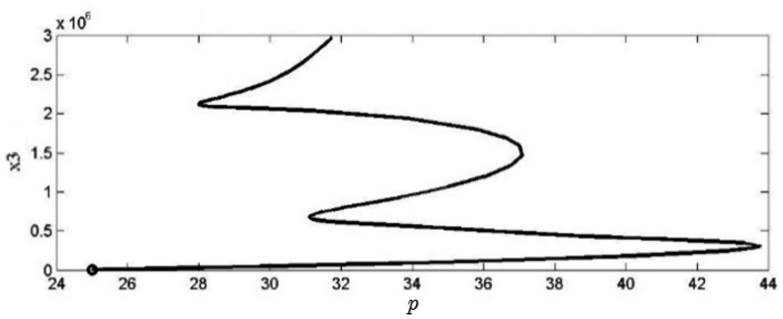

a)

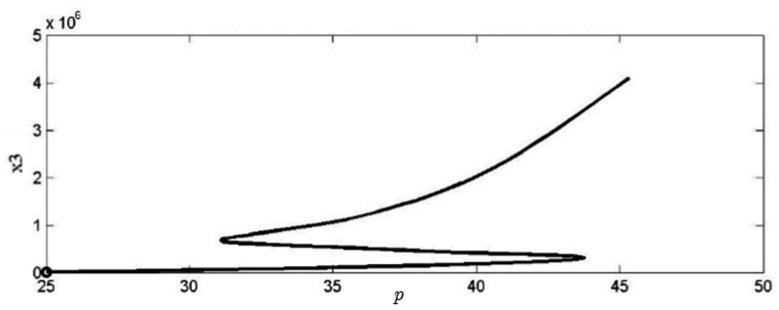

b)

Source: generated by the authors using the information system "Shadow economy" 


\section{Conclusion}

Based on computational experiments with a complex of models of the legal and shadow economies interaction, the dynamics of solutions was analyzed.

The analysis of phase trajectories projections that are formed by solutions of the interaction model of legal and shadow economies allows reaching the conclusion that the savings of members of society with constant incomes have specific points, where the trajectory returns in the opposite direction. It describes the singular "reverse-directed" economic processes. For members of different social groups, such "turns" occur at different times.

Economic analysis of simulation results shows that the shadow economy can be overcome. It is necessary to implement a set of measures that take into account the general macro-economic trends of legal and shadow sectors interaction.

\section{Acknowledgements}

This project has been funded with support from the European Commission (No. 204521-1-2011-1-LT-ERA MUNDUS-EMA21). This publication reflects the views of the authors only, and the Commission cannot be held responsible for any use which may be made of the information contained therein.

\section{References}

Alm, J., and Embaye, A. (2013). Using Dynamic Panel Methods to Estimate Shadow Economies around the World, 1984-2006. Public Finance Review, 41(5): 510-543.

Buyak, L., and Vinnychuk, I. (2009). Modelling of Shadow Economic Activity in Ukraine. Scientific Bulletin of Chernivtsi University: Series "Economics", 456: 130-138.

Chernavskii, D.S., Starkov, N.I., and Shcherbakov, A.V. (2002). On Some Problems of Physical Economics. Physics-Uspekhi, 45(9): 1045-1066.

Gonzalez-Fernandez, M., and Gonzalez-Velasco, C. (2014). Shadow Economy, Corruption and Public Debt in Spain. Journal of Policy Modeling.

Grygorkiv, V., and Vinnychuk, I. (2008). Mathematical Modeling of the Shadow Economy. The Twelve's International Scientific Conference Devoted to the Memory of Academician M. Kravchuk. Kyiv: 43 (Ukrainian).

Grygorkiv, V. S., Buyak, L. M., and Pauchok, V. K. (2008). Modeling the Interaction of Legal and Shadow Economies at the Macro Level. Cybernetics and Systems Analysis, 44(1): 100-106.

Gubarieva, I. (2013). Dynamic Simulation of the Regional Socio-economic Development Scenarios under the Shadow Economy Impact. Izvestiya of Irkutsk State Economics Academy, 5(91): 57-61.

Koljada, Y., and Semashko, E. (2014). Dynamic Risk Co-existence of Legal and Shadow Economy through Plane Non-linear Mathematical Model of Economic Dynamics. Young Scientist, 6(9): 145147 (Ukrainian).

Orviska, M., Caplanova, A., Medved, J., and Hudson, J. (2006). A Cross-section Approach to Measuring the Shadow Economy. Journal of Policy Modeling, 28: 713-724.

Svetunkov, S. (2012). Complex-valued Modeling in Economics and Finance. New York: Springer, p. 318.

Vinnychuk, I., and Ziukov, S. (2013). Shadow Economy in Ukraine: Modelling and Analysis. Business Systems \& Economics, 3(2): 141-152.

Vitlinskii, V., and Koliada, Y. (2010). Analytical Evaluation of Dynamics of Risk of Economic Evolution Taking into Account Corruption and Shadow Economy. Scientific Bulletin of Zaporizhzhya National University, 1(5): 84-88 (Ukrainian). 


\title{
LEGALIOS IR ŠEŠĖLINĖS EKONOMIKŲ SĄVEIKOS MODELIS: FAZINĖS TRAJEKTORIJOS PROJEKCIJOS TYRIMAS
}

\author{
Vasyl GRYGORKIV \\ Igor VINNYCHUK \\ Jurijaus Fedkovičiaus Černivcių nacionalinis universitetas, \\ Ukraina
}

Santrauka. Straipsnis skirtas teorinio, metodologinio ir metodinio požiūrių plètrai modeliuojant legalios ir šešèlinès ekonomikų komponentų tarpusavio sąveikos procesus. Šiame straipsnyje pristatytas legalios ir šešèlinès ekonomikų sąveikų matematinis modelis atsižvelgiant ị ekonominę visuomenès struktūrą.

Reikšminiai žodžiai: šešèlinė ekonomika, ekonominė visuomenès struktūra, fazinė trajektorija, ekonominè dinamika, simuliacija. 